\title{
The specific of the manifestations of the motivational sphere of higher school students of different areas of professional training
}

\author{
Elena Tkach $^{1, *}$, Olga Perets ${ }^{1}$ \\ ${ }^{1}$ Pacific National University, Khabarovsk, Russia
}

\begin{abstract}
The paper presents the results of a study devoted to identifying the features of the motivational sphere of higher school students in different areas of professional training. The empirical research was conducted on the basis of the Far Eastern State Transport University (Khabarovsk). The empirical study involved students of 1-3 years of study in the humanities and technical areas of training. Sixty students participated in the study (30 students studying in the humanities, 30 students studying in technical areas of training). In the conducted empirical research, it was found that the motivational sphere of students of different training areas has specificity. To maintain high motivation, it is important for students of the humanities to be satisfied with their professional decisions, to be satisfied with their activities, to be useful to society with their work, to strive for diversity, to develop mentally, morally, ethical, creatively and physically. In order to maintain a high level of motivation, students of technical areas of professional training need to be aware of the world of the profession, be able to plan their professional life, and be able to make professional decisions independently, they have almost no fear of making mistakes and receiving criticism and punishment for mistakes.
\end{abstract}

\section{Introduction}

The motivational sphere of a person is a system of factors, conditions and means, motives, needs, attitudes, and other social and psychological phenomena that significantly affect its development and formation. In modern conditions of social development, the problem of developing the motivational sphere of a modern student's personality becomes particularly relevant. The very problem of studying the motivational sphere of a student's personality in psychological science is one of the most popular. This is due to the fact that rethinking one's place in society, re-evaluating the significance of many value orientations, and taking responsibility for the results of life are hidden in the individual's motives and require management. In psychological and pedagogical science, a personality-oriented approach is associated with a deep interest in the motivational sphere of students' personality as subjects of educational relations, factors, conditions and means of activating its development in the context of professional formation.

\footnotetext{
*Corresponding author: elenat3004@mail.ru
} 
Motivation is the basis of any activity, including educational. Scientists dealing with the problem of motivation of educational activity emphasize the great importance of its development and preservation. It is educational motivation that guarantees the formation of cognitive activity, the development of thinking, and the acquisition of knowledge necessary for the successful professional activity of personality. The basis of successful educational and then professional activities is a high level of motivation for this type of activity. However, at present, when there is a huge amount of information provided by such sources as the media, the Internet, and social networks, it is very difficult to motivate a student to systematic study, systematic work with educational literature, and effective use knowledge in the training process.

\section{Main part}

Various modern authors have addressed the description and analysis of the manifestations of the motivational sphere of students in their research $[1,2,3,4,5,6,7,8,9,10,11,12,13$, 14,15 and others].

It should be noted that while studying at the higher educational institution, the psychological foundation of the professional activity of the future specialist is formed. Mastering a profession is a rather long and complex process that has internal patterns and qualitatively peculiar stages. Of particular importance in the development of a person as a professional is the period of development of educational and professional activities. In the motivation of students' educational and professional activities, a distinctive feature is that the educational and professional components of motivation are constantly combined with each other. The strength of motivation and its structure has a significant impact on the success of students' educational and professional activities.

In order to identify the specifics of the manifestations of the motivational sphere of students in different areas of training, we organized and conducted an empirical study on the basis of the Far Eastern State Transport University (Khabarovsk) in 2019. Sixty students participated in the study (30 students studying in the humanities, 30 students studying in technical areas of professional training).

The empirical study included the following stages:

1. The first stage - preparatory and search. At this stage, a theoretical analysis of the literature on the problem under study was carried out. The general area of the research was determined, adequate methods and techniques were selected, and primary materials were accumulated for further analysis and generalization.

2. The second stage is an empirical study. Empirical material was collected with the use of psychodianostic methods (the method "Diagnostics of personality for motivation to success" (T. Ehlers), the method "Motivation to avoid failures" (T. Ehlers), the method "Readiness for risk" (Schubert), the method "Professional readiness" (A. P. Chernyavskaya), the method "Determining the main motives for choosing a profession" (E. M. Pavlutenkov), the method "Motives for choosing a profession" (R. V. Ovcharova)).

Statistical analysis methods were used to process the obtained data.

Spearman's R-correlation coefficient was used to identify the relationship between the components of the motivational sphere of students of different training areas. The calculation was performed using the "SPSS Statistics 17.0" program. The results are presented in the tables. Correlation analysis was carried out for each group of students studying in the humanities and technical areas of professional training. For our description, we take a stronger relationship at the significance level $\mathrm{p} \leq 0.01$.

Table 1. Results of correlation analysis (manifestations of components of the motivational sphere of students of humanitarian areas of professional training). 


\begin{tabular}{|c|c|c|c|c|c|c|c|c|c|c|c|c|}
\hline & $\begin{array}{c}\text { ISS } \\
\text { M }\end{array}$ & $\begin{array}{c}\text { EN } \\
\text { M }\end{array}$ & A & Inf & PI & $\begin{array}{c}\text { Soc } \\
\mathbf{M}\end{array}$ & $\begin{array}{c}\text { Mor } \\
\text { M }\end{array}$ & $\begin{array}{c}\text { Aesth } \\
\text { M }\end{array}$ & $\begin{array}{c}\text { Cog } \\
\mathbf{M}\end{array}$ & CM & $\begin{array}{c}\text { Mat } \\
\text { M }\end{array}$ & UM \\
\hline MS & & & & & & & & & & & $.407^{*}$ & $\underset{*}{.697 *}$ \\
\hline EPM & $.416^{*}$ & .441 & & & & & & & & & & \\
\hline IISM & $.528^{*}$ & & & & & & & & & & $.453^{*}$ & \\
\hline DM & & & $.380^{*}$ & & .421 & & $.383^{*}$ & $.427^{*}$ & & & & \\
\hline $\mathrm{Pl}$ & & & $.572^{*}$ & .459 & Rep & & & & $.388^{*}$ & & & $\begin{array}{c}- \\
.369^{*}\end{array}$ \\
\hline EmA & & & $\underset{*}{.648^{*}}$ & & & & & & & & & \\
\hline SocM & & & & & & Rep. & & $.470^{* *}$ & & & & \\
\hline MorM & & & & & & & Rep. & $.612^{* * *}$ &. $.57_{*}^{*}$ & $\underset{*}{.695^{*}}$ & & \\
\hline $\begin{array}{c}\text { Aesth } \\
\text { M }\end{array}$ & & & & & & & & Rep. & $.514^{*}$ & & & \\
\hline $\mathrm{CM}$ & & & & & & & & $.575^{* *}$ & $.451^{*}$ & Rep. & & \\
\hline $\mathrm{RCW}$ & & & & .419 & & $.369^{*}$ & & & $.374^{*}$ & & & \\
\hline MatM & & & & & & & & & $.424^{*}$ & & Rep. & \\
\hline PM & & & & & & & $.531^{* * *}$ & $.541^{* * *}$ & $.367^{*}$ & $.391^{*}$ & $.377^{*}$ & \\
\hline
\end{tabular}

Note: MS - motivation to success, EPM - external positive motives, IISM - internal individual-significant motives, DM - decision - making, Pl - planning, EmA - emotional attitudes, SocM - social motives, MorM - moral motives, AesthM - aesthetic motives, CM - creative motives, RCW-related to the content of work, MatM - material motives, PM prestigious motives, ISSM - internal socially significant motives, ENM-external negative Motives, A -Autonomy, Inf- awareness, $\operatorname{Cog} \mathrm{M}$-cognitive motives, UM - utilitarian motives.

Using the Spearman correlation analysis, close relationships were established between success motivation and utilitarian motives $(\mathrm{r}=0.697)$ in a group of students in the humanities $(\mathrm{p} \leq 0.01)$. This empirical fact shows that students with high motivation for success have a pronounced desire to lead people, an interest in ease, economy, productivity and reliability of work.

A relationship was found between internal socially significant motives and internal individually significant motives $(r=0.528)$ at the significance level $p \leq 0.01$. This means that if the student's priority is the opportunity to benefit society with their work and achieve good results, then the priority will also be the development of mental and physical abilities for the chosen profession, the ability to communicate, display their creative abilities, the significance of the chosen profession for the student and the satisfaction brought to work. 
The association of the "autonomy" scale with the "planning" scale $(r=0.572)$ and the "emotional attitude" scale $(r=0.648)$ was found at the significance level $p \leq 0.01$. This indicates that high satisfaction with a professional decision (choice of profession, place of study and place of work) correlates with good emotional involvement (life optimism, emotional balance and tolerance of failures) and the ability to plan your professional life.

In addition, according to the data obtained, "aesthetic motives" for students of humanitarian areas of professional training are associated with the indicators "social motives" ( $\mathrm{r}=0.470)$, "moral motives" $(\mathrm{r}=0.612)$, "cognitive motives" $(\mathrm{r}=0.514)$, "creative motives" $(\mathrm{r}=0.575)$ and "prestige motives" $(\mathrm{r}=0.541)$ at the significance level $\mathrm{p} \leq 0.01$. These relationships indicate that a high desire to get satisfaction from work, the desire for aesthetics, harmony and beauty of work, contribute to a high desire to support social progress with their work, strive to improve their moral appearance, develop moral qualities, mastery of special knowledge, knowledge of the content of a particular work, also be original in work, getting opportunities for creativity and strive for professions that are valued among friends, allow you to achieve a prominent position in society, provide rapid promotion.

The indicator "moral motives" for students of humanitarian areas of professional training correlates with the indicators "cognitive motives" $(r=0.575)$, "creative motives" $(r=0.695)$ and "prestige motives" $(\mathrm{r}=0.531)$ at the significance level $\mathrm{p} \leq 0.01$. This empirical fact shows that a person's strong desire to improve their moral appearance, develop moral qualities, contributes to a high desire to master special knowledge, knowledge of the content of a particular work, to show originality in work, to get the "ground" for creativity, to show a strong desire for professions that are valued among friends, allowing to achieve a prominent position in society, ensuring rapid promotion.

Table 2. Results of correlation analysis (manifestations of components of the motivational sphere of students of technical areas of professional training).

\begin{tabular}{|c|c|c|c|c|c|c|c|c|c|c|c|c|c|}
\hline & MS & $\mathbf{R R}$ & $\begin{array}{c}\text { ISS } \\
\text { M }\end{array}$ & A & Inf & Pl & $\begin{array}{c}\mathbf{E m} \\
\mathbf{A}\end{array}$ & $\begin{array}{c}\text { Soc } \\
\text { M }\end{array}$ & $\begin{array}{c}\text { Mor } \\
\text { M }\end{array}$ & $\begin{array}{c}\text { Aeth } \\
\text { M }\end{array}$ & $\begin{array}{c}\text { Cog } \\
\text { M }\end{array}$ & $\underset{\text { Mat }}{\text { Mat }}$ & $\mathbf{U M}$ \\
\hline $\begin{array}{c}\text { MA } \\
\text { F }\end{array}$ & & & & & & & $\begin{array}{c}- \\
.468\end{array}$ & & & $-.367^{*}$ & & & $\begin{array}{l}.39 \\
4^{*}\end{array}$ \\
\hline EPM & $\begin{array}{l}- \\
.42 \\
2^{*}\end{array}$ & & .487 & & & & & & & & & & \\
\hline $\begin{array}{c}\text { EN } \\
\text { M }\end{array}$ & & & & $\begin{array}{c}- \\
.462 \\
*\end{array}$ & $\begin{array}{c}- \\
.398 \\
*\end{array}$ & & $\underset{* *}{-}$ & & & & & & \\
\hline IISM & & & .791 & & & & & & & & & & \\
\hline A & & & & Rep. & & .612 & & & & & & & \\
\hline $\operatorname{Inf}$ & & & & .695 & Rep. & .370 & & & & $.476^{* *}$ & & & \\
\hline $\mathrm{DM}$ & & & & .523 & .466 & .481 & .449 & & & & & & \\
\hline EmA & & & & .665 & $\underset{* * *}{\mathbf{5 8 8 2}}$ & .496 & Rep. & & & & & & \\
\hline
\end{tabular}




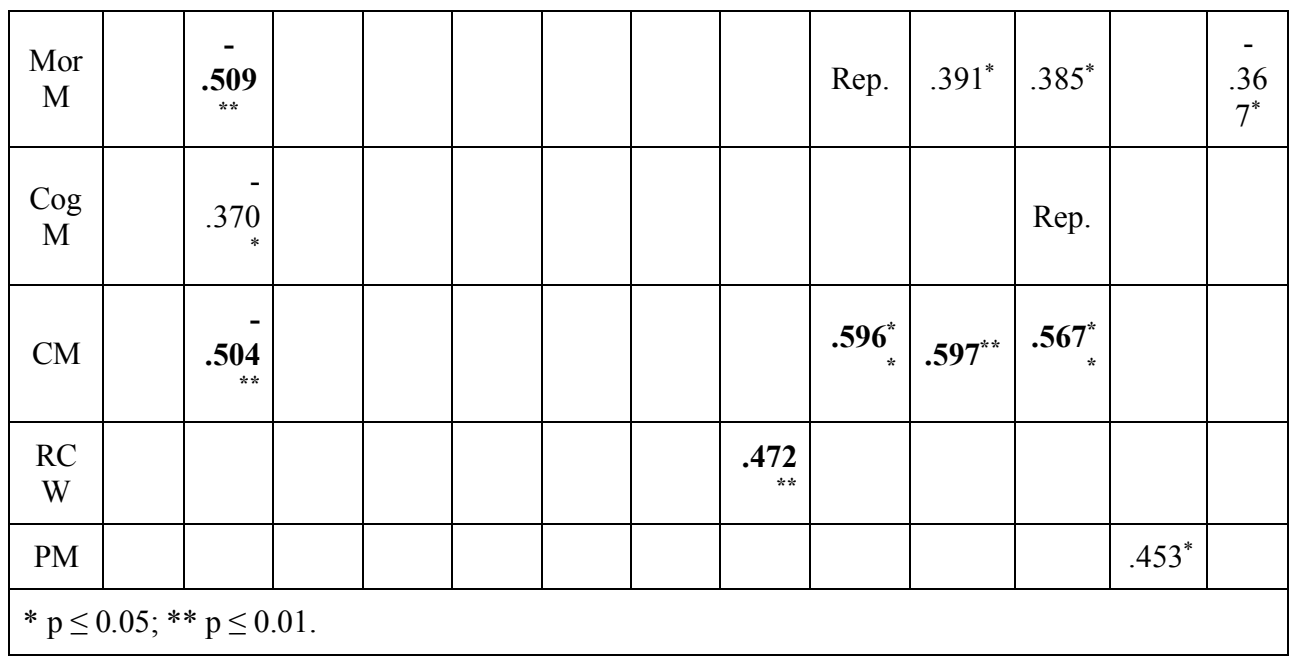

Note: MAF - motivation to avoid failures, EPM - external positive motives, ENM external negative motives, IISM-internal individually significant motives, A - autonomy, Infawareness, DM - decision - making, EmA - emotional attitude, MorM - moral motives, CogM-cognitive motives, $\mathrm{CM}$ - creative motives, $\mathrm{RCW}$ - related to the content of work, PM -prestigious motives, MS - motivation to success, RR - readiness for risk, ISSM - internal socially significant motives, $\mathrm{Pl}$ - planning, SocM-social motives, AethM - aesthetic motives, MatM - material motives, UM - utilitarian motives.

Using a correlation analysis (according to Spearman) in a group of students of technical areas of professional training, it was found that the indicator "emotional attitude" has a positive correlation with "autonomy" $(\mathrm{r}=0.665)$, "planning" $(\mathrm{r}=0.496)$ and a negative one with "motivation to avoid failures" $(r=-0.468)$ and with "external negative motives" $(r=$ 0.503 ) at the significance level $\mathrm{p} \leq 0.01$. This indicates that high emotional involvement (life optimism, emotional balance and tolerance of failures) to the chosen work is accompanied by a high satisfaction with the professional decision (choice of profession, place of study and place of work) and the ability to plan your professional life. This may indicate that with high emotional involvement, there is almost no fear of being wrong or making a mistake, or being criticized and punished for mistakes.

The relationship between internal socially significant motives and external positive motives $(r=0.487)$, as well as with internal individually significant motives $(r=0.791)$, at the significance level $p \leq 0.01$, was revealed for students of technical areas of professional training. This means that if the student's priority is the opportunity to benefit society with their work and achieve good results, then the priority will also be the development of mental and physical abilities for the chosen profession, the ability to communicate, display their creative abilities, the significance of the chosen profession for the student and the satisfaction brought to work, and important component is the location of the place of study and work.

The indicator "decision making" correlates with the indicators "autonomy" $(\mathrm{r}=0.523)$, "planning" ( $\mathrm{r}=0.481)$, at the significance level $\mathrm{p} \leq 0.01$. This empirical fact shows that if a student is able to make important professional decisions independently, then he is characterized by satisfaction with the professional decision (choice of profession, place of study and place of work) and the ability to plan his professional life.

The indicator "creative motives" positively correlates with "moral motives" $(\mathrm{r}=0.596)$, "aesthetic motives" ( $\mathrm{r}=0.597)$, "cognitive motives" $(\mathrm{r}=0.567)$ and negatively correlates with "readiness for risk" $(r=-0.504)$, at the significance level $\mathrm{p} \leq 0.01$. These relationships indicate that the higher the desire to be original in work, getting opportunities for creativity, the higher the desire to improve their moral appearance, the development of moral qualities; 
the desire to get satisfaction from work, the desire for aesthetics, harmony and beauty of work, the stronger the desire to contribute to social progress through their work; the desire to master special knowledge, knowledge of the content of a particular work. And the higher the desire to be original in work, to get opportunities for creativity, the lower the readiness for risk.

The relationship between autonomy and planning $(r=0.612)$ at the significance level $\mathrm{p} \leq$ 0.01 was revealed for students of technical areas of professional training. This means that if a student has a high level of satisfaction with a professional decision (choosing a profession, place of study, and place of work), then they have the ability to plan their professional life.

In addition, "awareness" is associated with the indicators "autonomy" ( $r=0.695)$, "decision-making" $(\mathrm{r}=0.466)$, "emotional attitude" $(\mathrm{r}=0.582)$, "aesthetic motives" $(\mathrm{r}=$ $0.476)$, at the significance level $p \leq 0.01$. These relationships indicate that the higher the student's awareness of the chosen specialty and the world of the profession as a whole, the higher the ability to plan their professional life, good emotional involvement (life optimism, emotional balance and tolerance of failures) to the chosen work and the desire to get satisfaction from the activity, the desire for aesthetics, harmony and beauty of work.

An inverse relationship was established between the "readiness for risk" scale and the "moral motives" scale $(r=-0.509)$, at the significance level $\mathrm{p} \leq 0.01$. This indicates that the higher the readiness for risk, the lower the desire to be original in work, to get opportunities for creativity, the higher the desire to improve one's moral appearance and develop moral qualities.

A relationship was found between the scale "related to the content of work" and "social motives" $(r=0.472)$, at the significance level $p \leq 0.01$. This indicates that the stronger the clear knowledge about the labor process, the focus on mental and physical labor, the higher the desire to contribute to social progress through their work.

The Mann-Whitney U-test was used to identify statistically significant differences. The calculation was performed using the program "SPSS Statistics 17.0". Results of a comparative analysis of the motivational sphere of students of the humanitarian and technical areas of professional training. The results are shown in table 3.

Table 3. The intensity of indicators of the motivational sphere of students of different areas of professional training.

\begin{tabular}{|c|c|c|c|c|}
\hline \multirow[b]{2}{*}{ Indicators } & \multicolumn{2}{|c|}{ Average } & \multirow[b]{2}{*}{$\begin{array}{c}\text { Mann- } \\
\text { Whitney } \\
\text { U-test }\end{array}$} & \multirow[b]{2}{*}{$\begin{array}{l}\text { The level of } \\
\text { statistical } \\
\text { significance } \\
\text { (p) }\end{array}$} \\
\hline & $\begin{array}{l}\text { Students of } \\
\text { the } \\
\text { humanitarian } \\
\text { areas of } \\
\text { professional } \\
\text { training }\end{array}$ & $\begin{array}{l}\text { Students of } \\
\text { the } \\
\text { technical } \\
\text { areas of } \\
\text { professional } \\
\text { training }\end{array}$ & & \\
\hline Motivation to success & 39.47 & 21.53 & 181.000 & $0.000 *$ \\
\hline Motivation to avoid failures & 28.35 & 32.65 & 385.000 & 0.339 \\
\hline Readiness for risk & 32.38 & 28.62 & 393.500 & 0.403 \\
\hline Internal socially significant motives, & 30.35 & 30.65 & 445.500 & 0.947 \\
\hline External positive motives & 31.28 & 29.72 & 426.500 & 0.727 \\
\hline External negative motives & 33.65 & 27.35 & 355.500 & 0.160 \\
\hline
\end{tabular}




\begin{tabular}{|l|c|c|c|c|}
\hline $\begin{array}{l}\text { Internal individually significant } \\
\text { motives }\end{array}$ & 30.32 & 30.68 & 444.500 & 0.935 \\
\hline Autonomy & 30.32 & 30.68 & 444.500 & 0.935 \\
\hline Awareness & $\mathbf{2 5 . 0 0}$ & $\mathbf{3 6 . 0 0}$ & $\mathbf{2 8 5 . 0 0 0}$ & $\mathbf{0 . 0 1 4}$ \\
\hline Decision - making & 27.48 & 33.52 & 359.500 & 0.179 \\
\hline Planning & 28.52 & 32.48 & 390.500 & 0.376 \\
\hline Emotional attitude & 30.67 & 30.33 & 445.000 & 0.941 \\
\hline Social & 32.02 & 28.98 & 404.500 & 0.496 \\
\hline Moral & 30.98 & 30.02 & 435.500 & 0.829 \\
\hline Aesthetic & 30.93 & 30.07 & 437.000 & 0.845 \\
\hline Cognitive & 34.13 & 26.87 & 341.000 & 0.097 \\
\hline Creative & 28.60 & 32.40 & 393.000 & 0.392 \\
\hline Related to the content of work & 28.35 & 32.65 & 385.500 & 0.334 \\
\hline Material & 30.52 & 30.48 & 449.500 & 0.994 \\
\hline Prestigious & 30.83 & 30.17 & 440.000 & 0.881 \\
\hline Utilitarian & 28.92 & 32.08 & 402.000 & 0.475 \\
\hline
\end{tabular}

Analysis of the data shown in the table allows us to draw the following conclusions:

1. Indicators on the scale of "Motivation to success" for students of the humanitarian areas of professional training are statistically higher than for students of technical areas of professional training at $\mathrm{p}=0.000$. This indicates that in the group of students in the humanities, compared to students of technical areas of professional training, the motivation for success is stronger.

2. Indicators on the "Awareness" scale are statistically higher for students of technical areas of professional training than for students of humanitarian areas of professional training (at $\mathrm{p}=0.014$ ), they are most characterized by awareness of the chosen specialty and the world of the profession as a whole.

\section{Conclusions}

Students in different areas of professional training revealed the specific of the manifestation of the motivational sphere. In a group of students of humanitarian areas of professional training, satisfaction with their professional decision (choosing a profession, place of study, and place of work), the opportunity to benefit society with their work, and achieving good results will be important for maintaining high motivation. They also have a high level of emotional involvement (life optimism, emotional balance and tolerance of failures), and the development of mental and physical abilities to match the chosen profession or chosen work. A high desire to get satisfaction from their work and be original in their work, a desire to support social progress with their work, to strive to improve their moral appearance, develop moral qualities, to master special knowledge, to know the content of a particular work, to get opportunities for creativity, will occupy one of the first places. 
In a group of students of technical areas of professional training, satisfaction with their professional decision (choosing a profession, place of study, and place of work), the ability to benefit society with their work, and achieving good results will also be important for maintaining high motivation. They also have a high level of emotional involvement (life optimism, emotional balance, and tolerance for failure), and the development of mental and physical abilities to match the chosen profession or work. The high desire to get satisfaction from their activities and be original in their work, the desire to support social progress with their work, to strive to improve their moral image, develop moral qualities, to master special knowledge, knowledge of the content of a particular work, to get opportunities for creativity, will occupy one of the first places. But in addition, students of technical areas of professional training have priority awareness of the chosen profession and the world of the profession as a whole, the ability to plan their professional life and the ability to independently make important professional decisions. With high emotional involvement, students of technical areas of professional training practically do not have the fear of being wrong or making a mistake, receiving criticism and punishment for mistakes.

The results of the comparative study allow us to note that for students of humanitarian areas of professional training, the motivation for success is more important than for students of technical areas of professional training; for students of technical areas of professional training, awareness about the chosen profession prevails in comparison with humanitarian areas of professional training.

\section{References}

1. M.V. Ajiev, World of science, culture, and education N4(71), 317-319 (2018) DOI: https://doi.org/10.24412/Fg6A0e6wPOU

2. E.L. Afanasenkova, Teacher education in Russia 10, 72-80 (2017) DOI: https://doi.org/10.26170/po17-10-11

3. T.O. Gordeeva, Siberian psychological journal 62, 38-53 (2016) DOI: https://doi.org/10.17223/17267080/62/4

4. T.O. Gordeeva, O.A. Sychev, Bulletin of the Moscow University. Series 14. Psychology 1 (2017) DOI: https://doi.org/10.11621/vsp.2017.01.69

5. A.V. Shumikhina, Russian psychological journal 5(4), 90-92 (2008) DOI: https://doi.org/10.24412/Fg6Ijm7IsjU

6. K.R. Sidorov, Bulletin of the Udmurt University. Series "Philosophy. Psychology. Pedagogy" 2, 40-41 (2014) DOI: https://doi.org/10.24412/Fg5AZCHzh0Y

7. S.T. Janerjan, A.E. Kim, Psychology and Psychotechnics 3, 1-12 (2018) DOI: https://doi.org/10.7256/2454-0722.2018.3.26311

8. A.N. Mikhailyuk, Russian psychological journal 8(3), 74-80 (2011) DOI: https://doi.org/10.21702/rpj.2011.3.8

9. Y.V. Saiko, N.I. Guslyakova, Bulletin of South Ural state University of Humanities and education 10, 209 (2013) DOI: https://doi.org/10.24412/Fg5AG3mu9Ng

10. N.V. Drozdova, Psychology and pedagogy: methods and problems of practical application 51, 40-44 (2016) DOI: https://doi.org/10.24412/Fg4_c4UeNbM

11. E.J. Zarubko, Internet journal "World of science. Pedagogy and psychology" 4, 6 (2018) DOI: https://doi.org/10.24412/Fg6KWdIVNg4

12. N.N. Vasyagina, E.L. Afanasenkova, J.A. Vedyashkina, S.A. Vasyagina, N.V. Abramovskih, The European Proceedings of Social \& Behavioural Sciences EpSBS PSYRGGU LXIV, 740 - 747 (2019) https://doi.org/10.15405/epsbs.2019.07.96 
13. A.P. Preobrazhensky, O.N. Choporov, Russian Journal of Education and Psychology 10(10), 109-113 (2019) DOI: 10.12731/2658-4034-2019-10-109-113

14. A.A. Grechko, Psychology and Psychotechnics 2, 16-26 (2020) DOI: 10.7256/24540722.2020.2.32460

15. J.A. Lukin, Higher education in Russia 27(8-9), 54-61 (2018) DOI: 10.31992/08693617-2018-27-8-9-54-61 